\title{
Predicting Hydrological Alterations to Quantitative and localized Climate Change in plateau regions: A case study of Lake Dianchi Basin
}

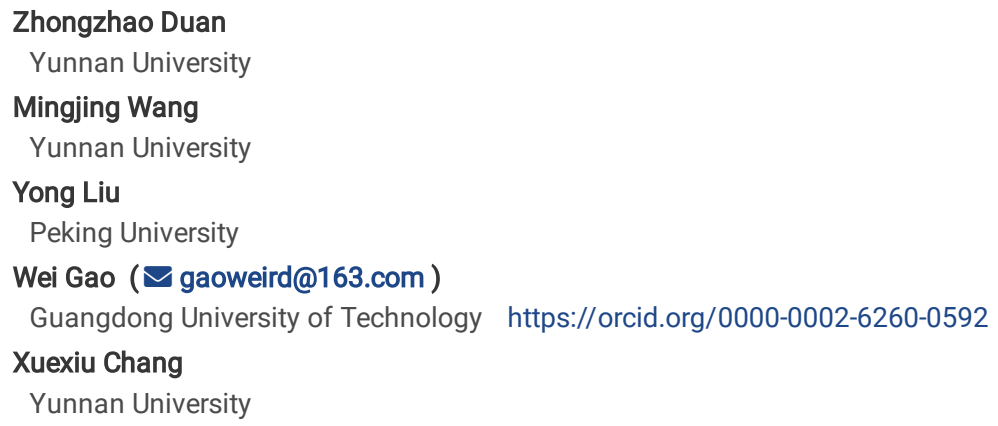

Version of Record: A version of this preprint was published at Stochastic Environmental Research and Risk Assessment on November 9th, 2021. See the published version at https://doi.org/10.1007/s00477-021-02126-6. 


\section{Abstract}

Climate change has greatly impacted hydrological regimes of lakes in sub-trophic and trophic areas. The uncertainties surrounding conventional future hydrological simulation methods with Coupled Model Intercomparison Project phase (CMIP) climate models have long been debated. However, it is crucial to obtain an accurate assessment result to help with better decision-making. In this study, we used the Lake Dianchi Basin (LDB) as a case study to demonstrate the use of a sub-catchment scale integrated model framework to obtain detailed hydrological simulation results and a comprehensive impact assessment of climate change on hydrological regimes. The results showed that 1) For the sub trophic lake basin LDB, its hydrological regimes are significantly impacted by climate change. Precipitation change impacted greater than air temperature change. 2) The 19 hydrological indicators showed large variations among the 18 climate scenarios. Precipitation impacted much greater than air temperature, and wet season might be impacted more by climate change. Climate change might impact more on 1/3/7-day minimums/maximums than 30/90-day minimums/maximums. 3) Enormous ecological and socio-economic risk for the LDB were indicated as its hydrologic regime is vulnerable to climate change. Among all six sub-catchments, Sub_06, characterized by a hilly landscape, would be impacted the most by climate change. 4) This study showed that, in regions with complex climatic conditions and topography, it is necessary to simulate hydrological states at the sub-catchment scale and differences of responses of each indicator to climate change should be fully considered.

\section{Introduction}

Climate change affects the hydrological cycle by changing the amount of precipitation, amount of extreme precipitation events, air temperature, and other meteorological factors (Grafton et al. 2013; Stocker and Raible 2005). The fifth Assessment Report (AR5) of the Intergovernmental Panel on Climate Change (IPCC) clarified that anthropogenic greenhouse gases caused the increase of recent global surface temperatures (IPCC 2014), and with this increase, the risk of extreme precipitation and extreme heat will increase sharply (IPCC 2012). The increasing intensity and frequency of extreme precipitation and extreme heat have resulted in the frequent occurrence of floods and droughts in some areas (Alexander et al. 2006; Min et al. 2011). Climate change has been proven to impact global hydrological regimes and water resources, and it will impose additional pressures in specific regions (Arnell 1999). Air temperatures and precipitation of inland high elevation areas are more susceptible to climate change than offshore low elevation areas, thus lead to their hydrological regimes are more vulnerable to climate change. (Snyder et al. 2003; Zhong et al. 2018). Lake Dianchi Basin (LDB) is a typical inland sub-trophic lake basin located in Yunnan-Guizhou Plateau of southwest China. It is densely populated and highly urbanized. Although its water resources are relatively abundant, the area's unevenly distributed precipitation and low per capital water availability cause the basin to experience seasonal flash floods and water scarcity. Thus, it is an ongoing challenge for the local government to reasonably allocate and efficiently utilize water resources.

A former study used HadCM3 climate model and Soil and Water Assessment Tool (SWAT) to investigate hydrological response to climate change of the LDB has indicated the great risk of runoff loss(Zhou et al. 2015a). However, the monotonous outputs of the HadCM3 climate model failed to capture the local climate characteristics and change possibilities of the LDB. since the spatial resolution were too coarse and the model only consider of precipitation decrease.

Accurate predictions of future water resource changes within the context of climate change are fundamental for scientific decision-making and reasonable stratagems. It required accurate climate scenarios to describe the local climate characteristics, precise hydrological models to simulate the hydrological regimes, and comprehensive indicators to conduct impact assessments. Massive studies have predicted and assessed the impact of climate change on hydrological regimes and water resources at different scales worldwide. However, such impact differed depending on climate models, regions, and selected indicators within current studies. A global scale study that employed 21 Coupled Model Intercomparison Project Phase 3 (CMIP3) climate models showed the runoff varied among regions (Arnell and Gosling 2013). Several recent studies that employed CMIP climate models have also shown regional variations (Schneider et al. 2013; Zhong et al. 2018; Zulkafli et al. 2016). The variations at the watershed scale are even greater (Alsafi and Sarukkalige 2018; Music et al. 2015; Yang et al. 2019), and few studies have focused on variations at the sub-watershed scale, which might be critical for areas with a highly spatially heterogeneous climate like the LDB.

When conducting hydrological impact and water resource risk assessments, different studies have applied separate indicators of preference. Indicators to assess impact and risk usually are categorized into two groups: interannual and seasonal indicators for evaluating overall changes, and extreme indicators for evaluating extreme hydrological events. These indicators are commonly used to either assess overall water resource changes or extreme hydrological risks (floods or droughts) (Asadieh and Krakauer 2017; Gu et al. 2018; Zhang et al. 2019), and differences among these indicators have been witnessed. Previous studies have shown the different responses of high and low peak flows to climate change (Brunner et al. 2019; Hoang et al. 2016), but few studies have focused on the variation of extremes at different time scales, which indicates multiple ecosystem risks (Richter et al. 1996). The importance of comprehensive indicators has gained some attention, but research on this subject is still lacking.

Based on physics, chemistry, and biology features, climate models represent the main process for interaction and feedback of various circles in the Earth's climate system as well as the mathematical equations associated with external forcing (Manabe 2019; Manabe and Wetherald 1967). These models are widely used in the study of climate change. The most commonly used climate models are the CMIP, including the General Circulation Models (GCMs) and Regional Climate Models (RCMs), of the IPCC. However, the CMIP5 climate model has a poor simulation accuracy in small watersheds and at the daily scale (Brown et al. 2015). Even the downscaled and bias-corrected CMIP climate model data cannot accurately describe the spatiotemporal characteristics of local climate at the watershed scale (Fang et al. 2018; Teng et al. 2012). A coarse spatial and temporal resolution and a lack of flexibility as well as differences in output results of different climate models (Jin et al. 2018) often lead to uncertainty in hydrological models (Joseph et al. 2018; Tian et al. 2013); this uncertainty is especially acute in urban areas (Ochoa-Rodriguez et al., 2015).

In general, using CMIP models and selecting appropriate indicators for evaluation at the watershed scale are common methods used to assess the impact of climate change on hydrological regimes. However, uncertainties of climate models, a lack of comprehensive indicators, and sub-watershed divisions may complicate efforts of applying simulation results difficult to decision-making processes and management work. Therefore, a model framework integrated with 
the Better Assessment Science Integrating Point and Nonpoint Sources-Climate Assessment Tool (BASINS-CAT), Hydrological Simulation Program-Fortran (HSPF), and Indicators for Hydrological Alteration (IHA) was developed in this study to obtain detailed hydrological simulation results. These results were used to assess the impact of climate change on hydrological regimes and the further risk that may be posed to the LDB.

\section{Materials And Methodology}

\subsection{Study Area}

Lake Dianchi $\left(24^{\circ} 29^{\prime} \mathrm{N}-25^{\circ} 28^{\prime} \mathrm{N}, 102^{\circ} 29^{\prime} \mathrm{E}-103^{\circ} 01^{\prime} \mathrm{E}\right)$ (Fig. 1) is the largest lake in the Yunnan-Guizhou Plateau, and is the sixth largest freshwater lake in China. Lake Dianchi Basin is the most populated and urbanized lake basin in the plateau. The lake area is approximately $300 \mathrm{~km}^{2}$, and the watershed covers a $2920 \mathrm{~km}^{2}$ area. There are 29 tributaries that flow into the LDB. The Yunnan-Guizhou Plateau is located in the high elevation (400-3500 m) area of southwest China $\left(22^{\circ}-30^{\circ} \mathrm{N}, 100^{\circ}-111^{\circ} \mathrm{E}\right)$. The climate of the Yunnan-Guizhou Plateau is highly heterogeneous attribute to the complex terrain and the subtropical monsoon climate. A study applied in the Upper Yangtze River basin showed that the plateau is more vulnerable to climate change than the plain regions (Yang et al. 2019). As the interface of the basins of the Pearl River, the Yangtze River and the Red River, the landform of the LDB is rugged and its precipitation has considerable spatial heterogeneity (Zhou et al. 2015b).

The climate of the LDB is a northern latitude subtropical plateau mountain monsoon climate. Influenced by monsoon patterns, the precipitation of the LDB is relatively abundant but unevenly distributed. There is an obvious dry season (May to October) and wet season (From November to April of the following year), with approximately $85 \%$ of the annual precipitation occurring in the wet season (Gao et al. 2020). Moreover, intensive precipitation and the loss of permeable surfaces caused by continued urbanization cause this basin and Kunming City (where the LDB is located) to experience severe flash flooding in the wet season. These similar floods have occurred in several highly urbanized Chinese cities like Kunming in recent decades. Despite the rich water resources in Lake Dianchi, the LDB's large population and high socio-economic development rate posed severe water scarcity risks in the dry season. To address this problem, the local government has constructed more than 30 reservoirs to store water, and since 2013, a cross-basin water diversion project was implemented to supply $5.72 \times 10^{8} \mathrm{~m}^{3}$ water for the LDB and Kunming City (Zhang and Wu 2020). The outlet Xianyuan Tunnel (built in 1996) and Haikou Brake (built in 1964) of the Haikou River were constructed to regulate the water level of Lake Dianchi to prevent flooding in the wet season and to preserve water in the dry season.

The geomorphology of the LDB has high spatial heterogeneity, as its elevation ranges from 1880 to $2837 \mathrm{~m}$. Relatively flat areas are located on the northern, southern, and eastern lake shores, whereas the western lake shore is surrounded by the Xishan Mountains (Fig. 1). The urban area is concentrated along the northern and northeastern lake shores, whereas most of the crop lands are concentrated along the eastern and southeastern shores (Table 1). Based on the digital elevation model (DEM), land use-land cover (LULC) data, and the tributaries characteristics, the LDB was divided into six sub-catchments. Sub_01 and Sub_02 are developed urban areas, Sub_03, Sub_04 and Sub_05 are in a state of pending development, where croplands are converted to wetlands and construction land, and Sub_06 covers the area of the Xishan Mountains.

Table 1. Elevation and LULC information for each sub-catchment and LDB.

\begin{tabular}{|llllllll|}
\hline Sub-Catchment & Elevation & \multicolumn{7}{l|}{ Area of each land use $\left(\mathrm{km}^{2}\right)$} & & & \\
\cline { 6 - 9 } & $(\mathrm{m})$ & Total & Cropland & Forest & Pasture & Water & Urban \\
\hline Sub_01 & $1880-2492$ & 166.3 & 27.8 & 42.7 & 23.7 & 5.3 & 66.8 \\
\hline Sub_02 & $1884-2837$ & 1155.1 & 245.9 & 544.2 & 161.2 & 14.0 & 189.7 \\
\hline Sub_03 & $1885-2344$ & 164.1 & 45.2 & 49.9 & 22.3 & 2.1 & 44.6 \\
\hline Sub_04 & $1885-2643$ & 798.3 & 239.5 & 290.0 & 202.3 & 13.8 & 52.7 \\
\hline Sub_05 & $1885-2014$ & 234.3 & 81.8 & 70.2 & 50.4 & 6.2 & 25.5 \\
\hline Sub_06 & $1885-2431$ & 60.0 & 11.6 & 21.2 & 22.6 & 2.0 & 2.6 \\
\hline LDB & $1880-2837$ & 2578.0 & 651.9 & 1018.2 & 482.6 & 43.5 & 381.9 \\
\hline
\end{tabular}

\subsection{Hydrological modeling Framework at the sub-catchment scale}

The structure of the model procedure in this study is shown in Fig. 2. First, BASINS-CAT was employed to synthesize localized climate change scenarios according to 27 historical climate time series and the IPCC 2015 and 2018 indicators. The HSPF was subsequently chosen to run the hydrological simulation to obtain daily runoff of the LDB. Finally, 16 extreme hydrological indicators calculated by the IHA and average annual and seasonal runoff were used to assess the impact of climate change on hydrological regimes and the further risks to the basin.

BASINS - CAT is based on the U.S. Environmental Protection Agency (EPA) BASINS4.0 version released in 2007, and it evaluates climate change through impact assessments to more effectively serve environmental management and decision-making (EPA 2009). When integrated with HSPF, the Soil and Water Assessment Tool (SWAT), and Storm Water Management Model (SWMM), BASINS-CAT can modify watershed or sub-catchment scale climate change scenarios to further simulate runoff and water quality. Specifically, BASINS-CAT provides flexible capabilities for creating climate change scenarios, allowing users to quickly assess a wide range of "what if" questions about how weather and climate could affect specific systems (EPA 2009).

HSPF, as one of the best semi-distributed hydrology and water quality models, has been applied in hundreds of studies. The HSPF was first developed based on the Stanford Watershed Model, and then integrated via BASINS of the EPA. The HSPF model adopts a top-down structural modeling approach to

Page 3/15 
modularize hydrology and water quality processes. Each module simulates a specific watershed process, and each module forms an input and output relationship with the other. The structure of HSPF include three calculation modules: pervious land segments (PERLND), impervious land segments (IMPLND), and reach or mixed reservoir segments (RCHRES), which can simulate runoff, sediment, and nutrients at an hourly time step. The main characteristic of PERLND is that it has a certain water seepage capacity. In the HSPF model, except for construction land, the rest of the land use types belong to this land type. IMPLND is an important feature module of the HSPF model, which mainly simulates the water balance and the relationship between pollutant accumulation and scour on impermeable ground in a built-up area. The capability to simulate PERLND and IMPLND is the most important reason for choosing the HSPF model in this study. The automatic calibration technique Model-Independent Parameter Estimation \& Uncertainty Analysis (PEST) was applied to calibrate and validate the HSPF model. Since Zhonghe is the only hydrological station with sufficient observed data, we use it to calibrate and validate the HSPF model. Parameters calibrated and validated with Zhonghe station (sub_02) were then transferred to all the sub catchments(Gao et al. 2015). Zhonghe Station is located in upstream area of LDB (Fig. 1), with low human influence and few water conservancy facilities, we considered it is appropriate to calibrate parameters for the basin.

\subsection{Localized Climate Change Scenarios}

To study the impacts of temperature and precipitation changes on the hydrological regime of the LDB, comparison scenarios for temperature increases (S_1.1-1.3) and precipitation increases (S_2.1-2.3) were first adopted. The AR5 (IPCC 2014) of IPCC addressed that the global mean surface temperature may increase by $1.0-2.0^{\circ} \mathrm{C}$ until 2065 and may increase by $1.0-3.7^{\circ} \mathrm{C}$ until 2100 in RCP.2.6 and RCP 8.5, respectively. The special report of IPCC (Global Warming of $1.5^{\circ} \mathrm{C}$ ) suggested to limit the increase of global mean surface temperature at $1.5^{\circ} \mathrm{C}$ by middle of the $21 \mathrm{st}$ century (IPCC 2018 ). Therefore, air temperature in this study was set to increase by $1.0,1.5$, and $2.0^{\circ} \mathrm{C}$ for $\mathrm{S}_{-} 1.1,1.2$, and 1.3 , respectively. IPCC also noted that an increase in air temperature would couple with an increase in the rainfall rate in sub-tropical and tropical regions (IPCC 2012); hence, it is of great importance to consider potential precipitation increases. The rainfall increasing rate coupled with the air temperature increase is unclear for the LDB. However, studying accurate responses of hydrological regimes to quantified climate change possibilities is one of the goals of this study. Hence, we set the total precipitation and extreme precipitation to increase by $10 \%, 15 \%$, and $20 \%$ relative to the air temperature. Because $85 \%$ of the total precipitation occurs in the wet season, the precipitation change in the wet season was incorporated, which addressed the state of extreme precipitation.

The study included six main scenarios and 16 sub-scenarios (Table 2). S_0.0 is the historical comparison scenario with no modification of any meteorological variable. S_1.1-1.3, S_2.1-2.3,S_3.1-3.3 denote modifications to the air temperature, total precipitation, and extreme precipitation, respectively. S_4.1-4.3 represented modifications of both air temperature and total precipitation, and S_5.1-5.3 represented modifications of both air temperature and extreme precipitation. The historical precipitation data from 27 national meteorological stations were matched to each sub-catchment for 1988-2018. Each subcatchment was matched with the stations located within or adjacent to the sub-catchment. If there was more than one station in the sub-catchment, an average value was used to represent the precipitation of the sub-catchment. Four meteorological stations gauged the air temperature; among them, data recorded by Kunming station was complete, hence, air temperature data from this station were utilized for the entire basin. Hamon evapotranspiration calculated by the Watershed Data Management Utility (WDMUtil) was used in the LDB.

Table 2

\begin{tabular}{|lllllllll|}
\hline Sub-Catchment & Elevation & \multicolumn{2}{l}{ Area of each land use $\left.\mathbf{( k m}^{2}\right)$} & & & \\
\cline { 3 - 7 } & $(\mathbf{m})$ & Total & Cropland & Forest & Pasture & Water & Urban \\
\hline Sub_01 & $1880-2492$ & 166.3 & 27.8 & 42.7 & 23.7 & 5.3 & 66.8 \\
\hline Sub_02 & $1884-2837$ & 1155.1 & 245.9 & 544.2 & 161.2 & 14.0 & 189.7 \\
\hline Sub_03 & $1885-2344$ & 164.1 & 45.2 & 49.9 & 22.3 & 2.1 & 44.6 \\
\hline Sub_04 & $1885-2643$ & 798.3 & 239.5 & 290.0 & 202.3 & 13.8 & 52.7 \\
\hline Sub_05 & $1885-2014$ & 234.3 & 81.8 & 70.2 & 50.4 & 6.2 & 25.5 \\
\hline Sub_06 & $1885-2431$ & 60.0 & 11.6 & 21.2 & 22.6 & 2.0 & 2.6 \\
\hline LDB & $1880-2837$ & 2578.0 & 651.9 & 1018.2 & 482.6 & 43.5 & 381.9 \\
\hline Modifications to air temperature, total precipitation, extreme precipitation for all 16 scenarios. \\
\hline
\end{tabular}

\subsection{Indicators for Hydrological Regime Alteration}

Indicators for Hydrological Alteration (IHA) were developed (Richter et al. 1996) for assessing the degree of hydrological alteration attributable to human influence. The Nature Conservancy (TNC) developed the IHA as a software for users to easily calculate characteristics of natural and altered hydrologic regimes. In this study, the IHA version 7 was applied to calculate hydrological regimes and hydrological extremes of both the LDB and each sub-catchment. The IHA is capable of calculating a total of 67 statistical parameters. These 67 parameters include 33 IHA parameters and 34 environmental flow component (EFC) parameters. Ten parameters of group 2 (extreme water conditions) were selected as indicators for extreme hydrological events. The group 2 parameters explained the magnitudes and duration of annual extreme water conditions, which represented a habitat's water situation in terms of both aquatic and terrestrial ecosystems. The high/low pulse threshold, count, and duration of parameter group 4 were selected to state the change and magnitude of the high/low flow. The high and low pulse dates of group 4 were not included because the change rates of both were below $10 \%$. In addition, the mean annual flow (mean flow in IHA), mean dry season flow, and mean wet season flow were calculated to analyze the changes in the annual and seasonal hydrological regime (Table 3). 
Table 3

\begin{tabular}{|c|c|c|c|c|}
\hline Explanation & Scenarios & $\begin{array}{l}\text { Air Temperature } \\
\left({ }^{\circ} \mathrm{C}\right)\end{array}$ & $\begin{array}{l}\text { Precipitation } \\
\text { (\%) }\end{array}$ & $\begin{array}{l}\text { Extreme Precipitation } \\
\text { (\%) }\end{array}$ \\
\hline Historic Data of 1988-2018 & S_0.0 & 0 & 0 & / \\
\hline \multirow[t]{2}{*}{ Temperature change comparison scenarios } & S_1.1 & 1.0 & / & / \\
\hline & S_1.2 & 1.5 & / & / \\
\hline \multirow[t]{3}{*}{ Precipitation change comparison scenarios } & S_2.1 & / & 10 & / \\
\hline & S_2.2 & / & 15 & / \\
\hline & S_2.3 & / & 20 & / \\
\hline $\begin{array}{l}\text { Extreme precipitation change } \\
\text { comparison scenarios }\end{array}$ & S_3.1 & / & / & 10 \\
\hline \multirow{2}{*}{ Temperature and precipitation change comparison scenarios } & S_4.2 & 1.5 & 15 & / \\
\hline & S_4.3 & 2.0 & 20 & / \\
\hline \multirow[t]{3}{*}{ Temperature and extreme precipitation change comparison scenarios } & S_5.1 & 1.0 & / & 10 \\
\hline & S_5.2 & 1.5 & / & 15 \\
\hline & S_5.3 & 2.0 & / & 20 \\
\hline
\end{tabular}

\section{Results}

\subsection{Hydrological Parameter Calibration}

Observed daily runoff data from Zhonghe National Hydrological Station were used to calibrate the hydrological parameters of HSPF. The model was calibrated from 2000 to 2009 and validated from 2010 to 2018 with the year of 1999 to be the warm-up period. The Nash-Sutcliffe efficiency coefficient (NSE), determination coefficient $\left(R^{2}\right)$ and relative error (RE) of the calibration period were $0.71,0.71$,-and $4.8 \%$ respectively, which indicated a close match between the simulated and observed data. The NSE, $R^{2}$, and RE were slightly lower $(0.76,0.83,19.7 \%$ respectively) throughout the validation period, but showed values of $0.72,0.71,1.2 \%$ respectively through the whole period (1999-2018); thus, we consider the parameter calibration result as highly acceptable. The proposed model demonstrated an acceptable performance in simulating extremely high values during both the calibration and validation period (Fig. 3 ). However, it occasionally overestimated peak flows during the validation period but underestimated them during the calibration period.

\subsection{Climate change on annual and seasonal runoff to Lake Dianchi}

\subsubsection{Annual Change}

Under S_0.0, from 1989-2018, the mean annual runoff (MAR) into Lake Dianchi was $9.24 \times 10^{8} \mathrm{~m}^{3} /$ a. For the air temperature scenarios (S_1), the most significant decrease happened under S_1.1, the MAR would decrease to $7.70 \times 10^{8} \mathrm{~m}^{3} / \mathrm{a}(16.68 \%)$, however under S_1.3, it would only decrease by $22.04 \%$ (Fig. 4a). For the total precipitation scenarios (S_2), the MAR consistently increased. Under S_2.1, the MAR would increase to $11.19 \times 10^{8} \mathrm{~m}^{3} / \mathrm{a}(21.12 \%)$, and would further increase to $13.22 \times 10^{8} \mathrm{~m}^{3} / \mathrm{a}(41.93 \%)$ under S_2.3. For the extreme precipitation scenarios (S_3), the MAR also consistently increased. Under S_3.1 and S_3.3, the MAR would increase by $19.03 \%$ and $38.49 \%$, respectively. For the compound scenarios (S_4, S_5), the MAR of the LDB would remain increase. The MAR will increase by $4.13 \sim 16.94 \%$ under S_4.1 4.3, respectively, and they would increase by $0.80 \%, 5.11 \%, 12.69 \%$ under S_5.1, S_5.2, and S_5.3, respectively.

\subsubsection{Seasonal change}

Under S_0.0, the mean dry season runoff (MDR) was $2.38 \times 10^{8} \mathrm{~m}^{3} /$ a and mean wet season runoff (MWR) was $6.86 \times 10^{8} \mathrm{~m}^{3} /$ a respectively. Single change in air temperature or precipitation impacted more on MWR. Under S_1 increase of MWR is about 1.5 times of the MDR, and under S_2 and S_3 increase of MWR is about 1.6 times of the MDR. For the compound scenarios, both the MDR and MWR increased. However, only when under S_4.1 and S_4.2, the increase of MDR is larger than that of the MER, otherwise, increase of the MDR is smaller than that of the MER.

\subsection{Climate change impact on hydrological extremes of the LDB}


Under S_1, all 16 indicators except for the low pulse count and high pulse count decreased from 6.03-37.21\% (Fig. 5). The 1-day minimum runoff decreased most $\left(37.21 \%, S \_1.3\right)$ and

the decrease in the minimums (17.4-37.21\%) was almost twice that of the maximums (14.01-23.19\%). The 1-, 3-, and 7-day minimums (average 32.52\%) decreased more than the 30- and 90-day minimums (average 23.9\%), whereas the 1-, 3-, and 7-day maximums (average 16.81\%) decreased less than the 30the 90-day minimums (average 20.34\%).

Under S_2 and S_3, all indicators except for the low pulse count, high pulse count and high pulse duration increased (17.27-55.26\% for S_2, 7.36-53.46\% for S_3). Under S_2, the increase of the maximums (25.61-55.26\%) was greater than that of the minimums (17.27-41.23\%), and under S_3, the increase of the maximums (24.67-53.46\%) was even greater than that of the minimums (7.36-21.92\%). The impacts of air temperature and precipitation changes showed inverse results to the low and high pulse thresholds.

Under compound scenarios changes of each indicator showed different trends compared with the former scenarios. Under S_4, all the maximums increased by up to $28.68 \%$. The 1-, 3-, and 7-day minimums decreased from 1.69-8.9\%, and only when total precipitation increased up to $20 \%$ (S_4.3) did they increase. For the 30- and 90-day minimums, most of the results increased once total precipitation increased. Under S_5, all the minimums decreased from - $2.99 \%$ to $-17.18 \%$, and all the maximums increased from $3.27-27.44 \%$.

\subsection{Spatial characteristics of Hydrological Regime and Extremes}

To comprehensively evaluate the variation among each sub-catchment, we used average value of the change percentage of each index under each scenario to express the total change. The high/low pulse counts were not included as they did not show substantial changes (Fig. 5).

Sub-catchment 06 was distinguished from the other five sub-catchments, as all of the former's 16 indicators proved to have a higher rate of change (from 70.07-80.26\%) than the others (-7.93-22.22\%) (Table 4). The other five sub-catchments showed a small variation (|coefficient of variation[CV]|ख0.1) for almost all the indicators except for the low pulse threshold (CV = 1.46), low pulse duration ( $C V=-0.85)$, high pulse duration $(\mathrm{CV}=36.17)$, 1 -day minimum $(\mathrm{CV}=$ $0.77)$, 3-day minimum (CV = 0.77), 9-day minimum ( $C V=0.7)$, and 30-day minimum ( $C V=0.19)$.

Table 4

\begin{tabular}{|c|c|c|}
\hline Indicators & Statistics & Explanations \\
\hline $\begin{array}{l}\text { IHA Group } 2 \\
\text { (10 indicators) }\end{array}$ & Annual maxima/minima 1-, 3-, 7-, 30-, 90-day mean. & $\begin{array}{l}\text { Magnitude and duration of annual extreme water } \\
\text { conditions. }\end{array}$ \\
\hline $\begin{array}{l}\text { IHA Group } 4 \\
\text { (6 indicators) }\end{array}$ & $\begin{array}{l}\text { Number of low/high pulses within each } \\
\text { water year. } \\
\text { Mean duration of low/high } \\
\text { pulses (days). }\end{array}$ & Frequency and duration of high and low flow. \\
\hline Mean annual flow/runoff & Average of annual daily flow. & Annual and seasonal flow/runoff states. \\
\hline $\begin{array}{l}\text { Mean dry season } \\
\text { flow/runoff }\end{array}$ & $\begin{array}{l}\text { Average of annual daily flow/runoff from November to April of the } \\
\text { next year. }\end{array}$ & \\
\hline $\begin{array}{l}\text { Mean wet season } \\
\text { flow/runoff }\end{array}$ & Average of annual daily flow/runoff from May to October. & \\
\hline
\end{tabular}

For all six sub-catchments, changes of the MAR, MDR, MWR varied considerably among the sub-catchments and scenarios (Fig. 6c). The MDR varied by much more (CV = 7.37) among the sub-catchments than the MAR (Fig. 5a, CV = 0.07) and MWR (Fig. 5b, CV = 0.41). Under S_1, the MAR, MDR and MWR of all the six sub-catchments decreased (2.16-45.18\%). Under S_2-S_5 only the MDR of Sub_06 significantly decreased (26.77\%-41.14\%), whereas the others increased by up to $63.83 \%$. For the MAR, Sub_06 increased the most under S_4 (9.63-18.52\%) and S_5 (7.41-18.52\%). For MDR, Sub_06 decreased the most (-42.9 $-45.18 \%)$ under S_1 and it continued to decrease under all scenarios. For the MWR, Sub_06 decreased the least under S_1 (2.16-8.25\%) and increased the most under S_2-S_5 (18.86-63.83\%).

Although Sub_06 had the greatest variation, variations in the other five sub-catchments occurred (Fig. 7). Under S_1, the 1-, 3-, and 7-day minimum runoff of Sub_04 decreased the least (-23.64 - -32.43\%). The minimum runoff rates of Sub_03 increased the most (32.43-81.08\%) under S_2, and the minimum runoff rates of Sub_02 increased the most under S_2 $(15.97=31.65 \%)$. Under S_4, the minimum runoff rates of Sub_05 increased the most $(0=15.38 \%)$. All the minimums decreased under S_5. Among them, the 1- and 3-day minimum runoff rates of Sub_04 decreased the least $(-9.7--11.52 \%$ and $-8.11--11.07 \%$, respectively), and the 7-day minimum runoff of Sub_01 decreased the least (-7.5 - -1.34\%).

\section{Discussion}

\subsection{Temporal responses of hydrological regimes to climate change}


Great variations of MAR proved to be a consequence of local climate characteristics, which are driven by monsoon precipitation that varies considerably on an annual basis. Like some other areas(Labriola et al. 2020), runoff of the LDB proved to be more sensitive to precipitation, as runoff changes caused by precipitation changes were almost twice those resulting from air temperature changes. The runoff change response to total precipitation change seemed to be linear, unlike the response to air temperature. When precipitation increased from $10-20 \%$, the increase in runoff subsequently doubled; when air temperature was raised by $2^{\circ} \mathrm{C}$ rather than $1^{\circ} \mathrm{C}$, the decrease in average annual runoff was not doubled, and most impacts of the air temperature increase happened within $1^{\circ} \mathrm{C}$. It is common knowledge that climate change has the largest impacts on tropical, sub-tropical, and monsoon regions (Maberly et al. 2020). Climate change impacts on runoff of the LDB were much greater than in middle latitude and low elevation areas. For instance, under the HadGEM1-TRIP A1B and A2 scenarios, the mean global river flow would increase from $4-8 \%$ (Falloon and Betts 2006), and in the Heihe River Basin of northwest China, a $2.0^{\circ} \mathrm{C}$ increase in air temperature is projected to decrease runoff by $2.0 \%$, and a $10 \%$ increase in precipitation is projected to increase runoff by $5.6 \%$ (Li et al. 2020 ).

When considering an air temperature increase with total precipitation (S_4.1-4.3) or an extreme precipitation increase (S5.1-5.3), we found that once the precipitation increased, both the mean annual and dry and wet season runoff would subsequently increase. This means that runoff losses caused by air temperature increases can be compensated for (the same level under S_0.0) by precipitation increases at the annual and seasonal scales.

Runoff changes in the dry and wet seasons seemed to have similar trends, but there were differences in their change amplitudes (Fig. 3b, $5 \mathrm{c}$ ). For example, an increase in extreme precipitation would cause the runoff rate to increase in the wet season by twice as much as that of the dry season. The dry season showed lower losses in runoff (S_1), whereas the wet season obtains more (S_2 and S_3) makes the runoff increase of the dry season is larger than the wet season when both air temperature and total precipitation increased (S_4). It can be benefit for dry season, however, if consider of hydrological extremes and flood risk, it can be concering.

The annual and seasonal runoff changes indicated that runoff loss caused by air temperature raise can be compensated for by both total and extreme precipitation increases. However, the hydrological extremes did not show similar results. The 1-, 3-, 7-day minimums were compensated for (the same level under S_0.0) only when the total precipitation increased up to $20 \%$ (S_4.3) as it maintained decrease. Most of the 30- and 90-day minimums increased once the total precipitation increased. However, all minimums decreased only if the extreme precipitation increased. Therefore, the minimum flow loss caused by the air temperature increase was not compensated for by extreme precipitation. Several studies have applied Indicators of Hydrological Alteration in Rivers (IAHRIS) to address the river flow alterations demonstrated by the variation among maximum (flood) and minimum (drought) extreme values (Arévalo-Mejía et al. 2020; López-Ballesteros et al. 2020). However, the different responses of extreme flows on different time scales were not revealed. In this study, 1-, 3-, 7, 30, and 90-day maximum and minimum high/low flow magnitudes and durations were calculated via the IHA, and the complicated responses of these indicators to climate change were revealed. In general, for the LDB, on the annual and seasonal scale, runoff losses caused by an air temperature raise could be compensated for by a precipitation increase. However, 1-, 3-, and 7-day minimum runoff rates reduced by air temperature increases could not be compensated for by a precipitation increase, which indicated a great ecological risk to aquatic ecosystems because low flows can critically shape habitats for aquatic organisms (Humphries and Baldwin 2003; Lake 2003).

\subsection{Spatial responds of hydrological regime to climate change}

The sub-catchment scale runoff changes showed great variation, and among them, the runoff of Sub_06 was impacted most by climate change. In addition to Sub_06, the other five sub-basins also showed great variation for extreme hydrological indicators. This was especially true for the low pulse duration and the 1-, 3-, and 7- day minimum runoff.

We identified Sub_06 as the most impacted sub-catchment with the highest stress risk posed by climate change. Under S_01, the mean annual and wet season runoff of Sub_06 decreased the least. However, its MDR decreased most. Under S_4 and S_5, the mean annual and wet season runoff of Sub_06 increased most, however, its MDR decreased the most whereas for the other five sub-catchments, the mean dry season flows all increased. Because the hydrological responses to climate change, topography, and land use proved to be complicated and the mechanisms behind them remain unclear, we have assumed that the high variation of Sub_06 may be attributed to its unique topography. The DEM showed that the terrain of Sub_06 is more rugged other areas, as its elevation ranged $546 \mathrm{~m}$ within an area of $60 \mathrm{~km}^{2}$. Additionally, Sub_6 contained the lowest construction land (0.7\%), and $92.3 \%$ of its land was covered by vegetation (crop land $34.9 \%$, forest $35.3 \%$, and grass land $37.6 \%$ ). In addition, the western mountains that surround Sub_06 comprise the only existing primeval forest in the Dianchi Basin. This represents the natural vegetation community and succession process of the area, which has a high biodiversity conservation value and has been identified as a nature reserve by the local government.

Several studies have demonstrated the spatial heterogeneity of hydrological responses to climate change at a detailed spatial scale (catchment scale) as attributed to local climate, topography, and land use characteristics. A study divided Mexico into 1150 catchments and showed demonstrable differences in the hydrological alterations between catchments as attributed to their varying topography and land uses (Arévalo-Mejía et al. 2020). Another study applied in the Elbow River watershed of the Rocky Mountains showed that the area's complex climate patterns were mainly driven by the impact degree of climate change on sub-catchment scale hydrological responses (Farjad et al. 2016).

The results of this study showed the necessity to conduct sub-catchment scale hydrological modeling in the LDB. A study applied in a reservoir-regulated basin of Lake Poyang noted that an increase in reservoir storage can be used to offset extreme climate and hydrological events, whereas reservoir capacity distribution and location are of great importance (Dong et al. 2020). If simulations are only performed at the watershed scale, risk differences among subcatchments cannot be identified. Moreover, detailed and specified information cannot be obtained, which may eventually lead to mistakes in future water use decisions and wasted investments.

\subsection{Study Limitation}


Instead of predicting future climate change and simulating watershed scale hydrological responses, this study explored the quantified, detailed responses of the hydrological regime of the LDB to climate change. Hence, CMIP climate models were excluded to reduce climate-based uncertainties. Although we processed sufficient scenarios that totally represented the climate special characteristics of the LDB, these could only be used for a quantitative assessment, not predictions. Most of the meteorological stations in the LDB were built after the 1980s, and we could only obtain complete precipitation observation data for 31 years at most. A standard document issued by Chinese Meteorological Administration recommended the use of 30 years as a period for climate studies. Within 1988-2018, extreme hydrological events such as the great flood of 1988 and the drought of 2010 were recorded; hence, the study period was representative. However, if more meteorological data could be obtained, the precipitation of the LDB could be described more accurately. The LDB is located in a high elevation subtropical area, and our study provided a regional reference for global climate impact assessments. However, the results shown in this study might be different from those based on lakes located in temperate and frigid areas, especially those with a frozen period and snowmelt supply. Therefore, more comprehensive impact assessments of different plateau lake types are needed.

\section{Conclusions}

The major conclusions of this study are summarized as follows:

1) For the sub trophic lake basin LDB, its hydrological regimes are significantly impacted by climate change, and precipitation change impacted greater than air temperature change.

2) The 19 hydrological indicators showed large variations among the 18 climate scenarios. Precipitation impacted much greater than air temperature, and wet season might be impacted more by climate change. Climate change might impact more on 1/3/7-day minimums/maximums than 30/90-day minimums/maximums. Besides, at the annual and seasonal scales, runoff losses caused by air temperature increases can be compensated for by precipitation increases. However, air temperature-related reductions to the 1-, 3-, 7-day minimum runoff rates could not be compensated for by a precipitation increase.

3) Enormous ecological and socio-economic risk for the LDB were indicated as its hydrologic regime is vulnerable to climate change. The response of each sub-catchment to climate change was demonstrably different. Among all six sub-catchments, Sub_06, characterized by a hilly landscape, would be impacted the most by climate change.

4) Taking the LDB as a case study, this research demonstrates that, in regions with complex climatic conditions and topography, it is necessary to simulate hydrological states at the sub-catchment scale and differences of responses of each indicator to climate change should be fully considered.

\section{Declarations}

Acknowledgement: We thank the Yunnan State Key Laboratory for Plateau Mountain Ecology and Restoration of Degraded Environments for providing the opening funding for this study.

\section{Declarations:Funding:}

This study was supported by National Natural Science Foundation of China (No. 41701631), Joint Grant of Yunnan Provincial Science and Technology Department - Yunnan University Major Project (2018FY001-007), Yunnan Science and Technology Major Project(2018BC002).

\section{Competing Interests:}

The authors declare that they have no conflict of interest to this work.

Availability of data and materials:Meteorological, digital elevation model (DEM), land use, and flow gauge data used in this study were available from Chinese National Center for Meteorological Data Science, Chinese Resource and Environment Science and Data Center, and Chinese National Science \& Technology Infrastructure.

Code availability:The BASINS-CAT and HSPF used in this study were open access software of the US EPA, and they can be downloaded from the EPA website. (https://www.epa.gov/ceam/basins-framework-and-features)The IHA software also was an open access software which can be downloaded from the web site of The Nature Conservancy.

(http://www.conservationgateway.org/ConservationPractices/Freshwater/EnvironmentalFlows/MethodsandTools/IndicatorsofHydrologicAlteration/Pages/IH, Software-Download.aspx)

Authors Contributions:Zhongzhao Duan, conceptual, writing, data process, model running.Mingjing Wang, conceptual, writing, data process, model calibration. Yong liu, conceptual, supervision, editing.Wei Gao, conceptual, editing, funding.Xuexiu Chang, conceptual, supervision, editing.

Ethical Approval:No animal or plant experiments were involved in this study. Meteorological, digital elevation model (DEM), land use, and flow gauge data used in this study were available from Chinese National Center for Meteorological Data Science, Chinese Resource and Environment Science and Data Center, and Chinese National Science \& Technology Infrastructure. This study does not harm the interests of any individual or organism by obtaining data.

Consent to Participate:No animal or plant experiments were involved in this study, therefore this study does not harm the interests of any individual or organism by obtaining data. 
Consent to Publish:The authors confirm that the work described has not been published before, and not under consideration for publication elsewhere. The publication of this manuscript has been approved by all co-authors.

\section{References}

Alexander LV et al. (2006) Global observed changes in daily climate extremes of temperature and precipitation Journal of Geophysical Research 111 doi:10.1029/2005jd006290

Alsafi H, Sarukkalige P (2018) Hydrological impacts of climate change on the future streamflow of three unregulated catchments of the Australian hydrologic reference stations International Journal of Hydrology Science and Technology

Arévalo-Mejía R, Leblois E, Salinas-Tapia H, Mastachi-Loza CA, Bâ KM, Díaz-Delgado C (2020) A baseline assessment of hydrologic alteration degree for the Mexican catchments at gauged rivers (2016) Science of The Total Environment 729:139041 doi:10.1016/j.scitotenv.2020.139041

Arnell N (1999) Climate change and global water resources Global Environmental Change 9:S31-S49 doi:10.1016/s0959-3780(99)00017-5

Arnell NW, Gosling SN (2013) The impacts of climate change on river flow regimes at the global scale Journal of Hydrology 486:351-364 doi:10.1016/j.jhydrol.2013.02.010

Asadieh B, Krakauer NY (2017) Global change in streamflow extremes under climate change over the 21st century Hydrology and Earth System Sciences 21:5863-5874 doi:10.5194/hess-21-5863-2017

Brown C, Brown E, Murray-Rust D, Cojocaru G, Savin C, Rounsevell M (2015) Analysing uncertainties in climate change impact assessment across sectors and scenarios Climatic Change 128:293-306 doi:10.1007/s10584-014-1133-0

Brunner MI, Farinotti D, Zekollari H, Huss M, Zappa M (2019) Future shifts in extreme flow regimes in Alpine regions Hydrology and Earth System Sciences 23:4471-4489 doi:10.5194/hess-23-4471-2019

Dong $\mathrm{N}$ et al. (2020) Water resources management in a reservoir-regulated basin: Implications of reservoir network layout on streamflow and hydrologic alteration Journal of Hydrology 586:124903 doi:https://doi.org/10.1016/j.jhydrol.2020.124903

EPA (2009) BASINS 4.0 Climate Assessment Tool (CAT): supporting documentation and user's manual.

Falloon PD, Betts RA (2006) The impact of climate change on global river flow in HadGEM1 simulations Atmospheric Science Letters 7:62-68 doi:10.1002/asl.133

Fang G, Yang J, Chen Y, Li Z, De Maeyer P (2018) Impact of GCM structure uncertainty on hydrological processes in an arid area of China Hydrology Research 49:893-907 doi:10.2166/nh.2017.227

Farjad B, Gupta A, Marceau DJ (2016) Annual and Seasonal Variations of Hydrological Processes Under Climate Change Scenarios in Two Sub-Catchments of a Complex Watershed Water Resources Management 30:2851-2865 doi:10.1007/s11269-016-1329-3

Gao W, Duan Z, Yan CA, Liu C (2020) Influence of nutrient mitigation measures on the fractional export of watershed inputs in an urban watershed Environmental Science and Pollution Research 27:18521-18529 doi:10.1007/s11356-020-08411-1

Gao W, Guo HC, Liu Y (2015) Impact of Calibration Objective on Hydrological Model Performance in Ungauged Watersheds Journal of Hydrologic Engineering 20:10 doi:10.1061/(asce)he.1943-5584.0001116

Grafton RQ et al. (2013) Global insights into water resources, climate change and governance Nature Climate Change 3:315-321 doi:10.1038/nclimate1746

Gu H, Yu Z, Yang C, Ju Q (2018) Projected Changes in Hydrological Extremes in the Yangtze River Basin with an Ensemble of Regional Climate Simulations Water 10 doi:10.3390/w10091279

Hoang LP et al. (2016) Mekong River flow and hydrological extremes under climate change Hydrology and Earth System Sciences 20:3027-3041 doi:10.5194/hess-20-3027-2016

Humphries P, Baldwin DS (2003) Drought and aquatic ecosystems: an introduction Freshwater Biology 48:1141-1146 doi:10.1046/j.1365-2427.2003.01092.x

IPCC (2012) Managing the risks of extreme events and disasters to advance climate change adaptation

IPCC (2014) Climate Change 2014: Synthesis Report. Contribution of Working Groups I, II and III to the Fifth Assessment Report of the Intergovernmental Panel on Climate Change. IPCC, Geneva, Switzerland

IPCC (2018) Summary for Policymakers. In: Global Warming of $1.5^{\circ} \mathrm{C}$. An IPCC Special Report on the impacts of global warming of $1.5^{\circ} \mathrm{C}$ above pre-industrial levels and related global greenhouse gas emission pathways,in the context of strengthening the global response to the threat of climate change, sustainable development, and efforts to eradicate poverty. In Press, 
Jin L et al. (2018) Modeling future flows of the Volta River system: Impacts of climate change and socio-economic changes Science of the Total Environment 637:1069-1080 doi:10.1016/j.scitotenv.2018.04.350

Joseph J, Ghosh S, Pathak A, Sahai AK (2018) Hydrologic impacts of climate change: Comparisons between hydrological parameter uncertainty and climate model uncertainty Journal of Hydrology 566:1-22 doi:10.1016/j.jhydrol.2018.08.080

Labriola LG, Ellis JH, Gangopadhyay S, Pruitt T, Kirstsetter P-E, Hong Y (2020) Evaluating the effects of downscaled climate projections on groundwater storage and simulated base-flow contribution to the North Fork Red River and Lake Altus, southwest Oklahoma (USA) Hydrogeology Journal 28:2903-2916 doi:10.1007/s10040-020-02230-x

Lake PS (2003) Ecological effects of perturbation by drought in flowing waters Freshwater Biology 48:1161-1172 doi:10.1046/j.1365-2427.2003.01086.x

Li Z, Li Q, Wang J, Feng Y, Shao Q (2020) Impacts of projected climate change on runoff in upper reach of Heihe River basin using climate elasticity method and GCMs Science of The Total Environment 716:137072 doi:10.1016/j.scitotenv.2020.137072

López-Ballesteros A, Senent-Aparicio J, Martínez C, Pérez-Sánchez J (2020) Assessment of future hydrologic alteration due to climate change in the Aracthos River basin (NW Greece) Science of The Total Environment 733:139299 doi:https://doi.org/10.1016/j.scitotenv.2020.139299

Maberly SC et al. (2020) Global lake thermal regions shift under climate change Nature Communications 11 doi:10.1038/s41467-020-15108-z

Manabe S (2019) Role of greenhouse gas in climate change** Tellus A: Dynamic Meteorology and Oceanography 71:1620078 doi:10.1080/16000870.2019.1620078

Manabe S, Wetherald R (1967) Thermal Equilibrium of the Atmosphere with a Given Distribution of Relative Humidity Journal of Atmospheric Sciences 24:241-259 doi:10.1175/1520-0469(1967)024<0241:TEOTAW>2.0.CO;2

Min S-K, Zhang X, Zwiers FW, Hegerl GC (2011) Human contribution to more-intense precipitation extremes Nature 470:378-381 doi:10.1038/nature09763

Music B, Frigon A, Lofgren B, Turcotte R, Cyr J-F (2015) Present and future Laurentian Great Lakes hydroclimatic conditions as simulated by regional climate models with an emphasis on Lake Michigan-Huron Climatic Change 130:603-618 doi:10.1007/s10584-015-1348-8

Richter BD, Baumgartner JV, Powell J, Braun DP (1996) A method for assessing hydrologic alteration within ecosystems Conserv Biol 10:1163-1174 doi:10.1046/j.1523-1739.1996.10041163.x

Schneider C, Laizé CLR, Acreman MC, Flörke M (2013) How will climate change modify river flow regimes in Europe? Hydrology and Earth System Sciences 17:325-339 doi:10.5194/hess-17-325-2013

Snyder MA, Sloan LC, Diffenbaugh NS, Bell JL (2003) Future climate change and upwelling in the California Current Geophysical Research Letters 30 doi:10.1029/2003gl017647

Stocker TF, Raible CC (2005) Water cycle shifts gear Nature 434:830-833 doi:10.1038/434830a

Teng J, Vaze J, Chiew FHS, Wang B, Perraud J-M (2012) Estimating the relative uncertainties sourced from GCMs and hydrological models in modeling climate change impact on runoff Journal of Hydrometeorology 13:122-139 doi:10.1175/JHM-D-11-058.1

Tian Y, Xu Y-P, Zhang X-J (2013) Assessment of Climate Change Impacts on River High Flows through Comparative Use of GR4J, HBV and Xinanjiang Models Water Resources Management 27:2871-2888 doi:10.1007/s11269-013-0321-4

Yang X et al. (2019) Estimating the response of hydrological regimes to future projections of precipitation and temperature over the upper Yangtze River Atmospheric Research 230 doi:10.1016/j.atmosres.2019.104627

Zhang H et al. (2019) Impacts of future climate change on water resource availability of eastern Australia: A case study of the Manning River basin Journal of Hydrology 573:49-59 doi:https://doi.org/10.1016/j.jhydrol.2019.03.067

Zhang R, Wu B (2020) Environmental Impacts of High Water Turbidity of the Niulan River to Dianchi Lake Water Diversion Project Journal of Environmental Engineering 146:05019006 doi:10.1061/(ASCE)EE.1943-7870.0001623

Zhong R, He Y, Chen X (2018) Responses of the hydrological regime to variations in meteorological factors under climate change of the Tibetan plateau Atmospheric Research 214:296-310 doi:10.1016/j.atmosres.2018.08.008

Zhou J et al. (2015a) Integrated SWAT model and statistical downscaling for estimating streamflow response to climate change in the Lake Dianchi watershed, China Stochastic Environmental Research and Risk Assessment 29:1193-1210 doi:10.1007/s00477-015-1037-1

Zhou J, Liang Z, Liu Y, Guo H, He D, Zhao L (2015b) Six-decade temporal change and seasonal decomposition of climate variables in Lake Dianchi watershed (China): stable trend or abrupt shift? Theoretical and Applied Climatology 119:181-191 doi:10.1007/s00704-014-1098-y

Zulkafli Z et al. (2016) Projected increases in the annual flood pulse of the Western Amazon Environmental Research Letters 11:014013 doi:10.1088/17489326/11/1/014013 


\section{Figures}

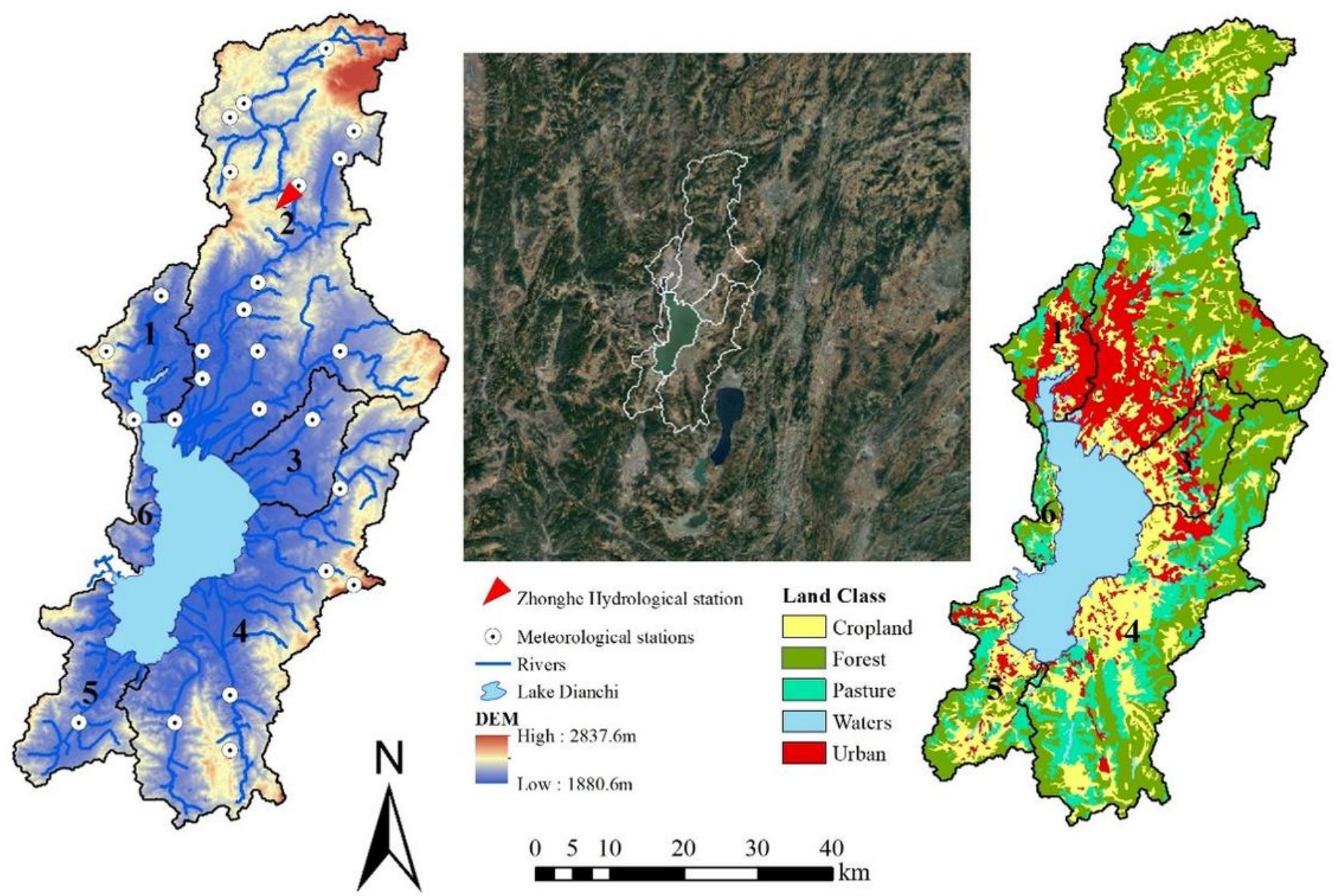

Figure 1

Land use-land cover (LULC) data, Digital Elevation Model (DEM), and Sub-catchment delineation of the Lake Dianchi Basin (LDB). Note: The designations employed and the presentation of the material on this map do not imply the expression of any opinion whatsoever on the part of Research Square concerning the legal status of any country, territory, city or area or of its authorities, or concerning the delimitation of its frontiers or boundaries. This map has been provided by the authors. 


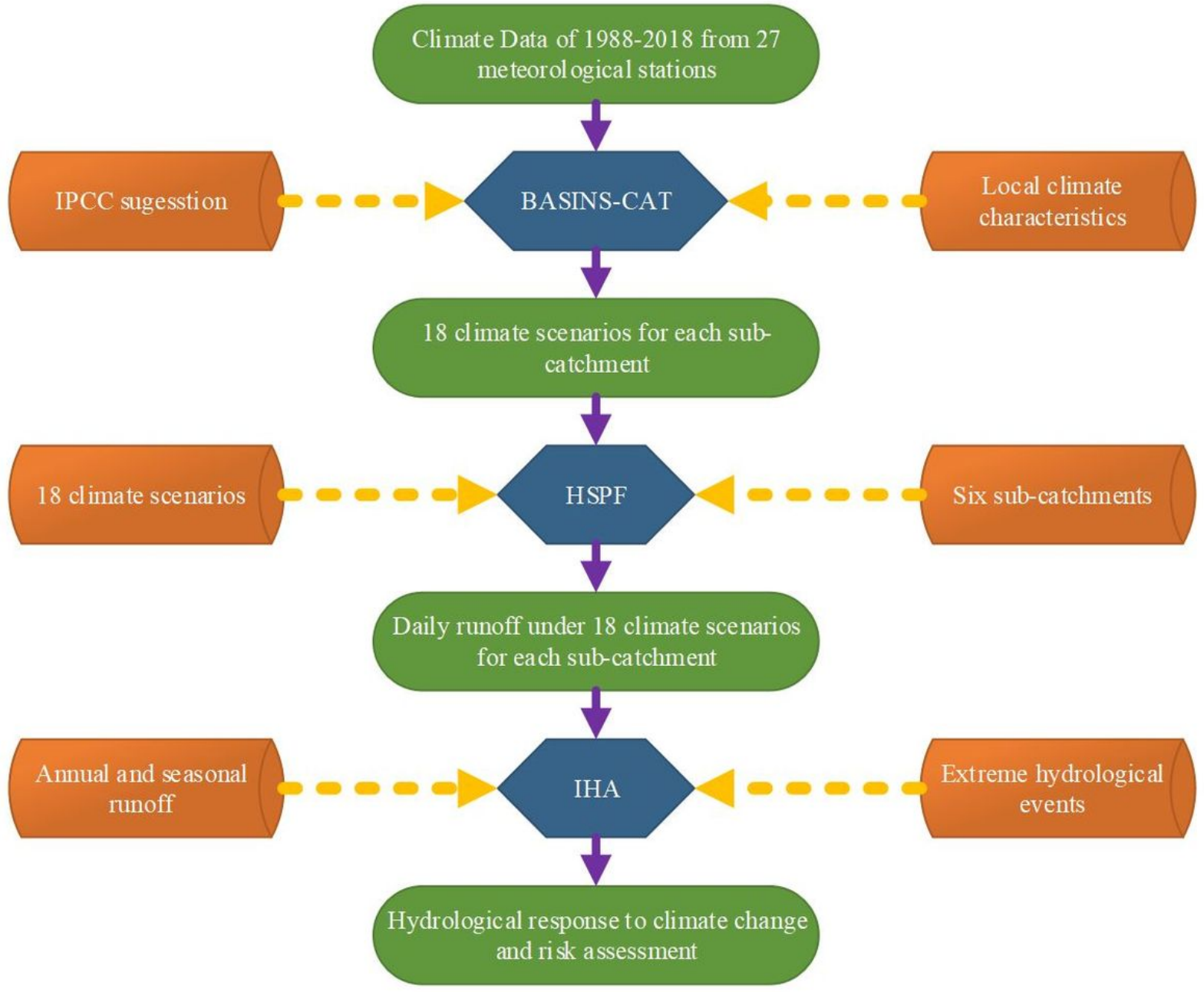

\section{Figure 2}

Schematic diagram of the hydrological modeling framework at the sub-catchment scale.

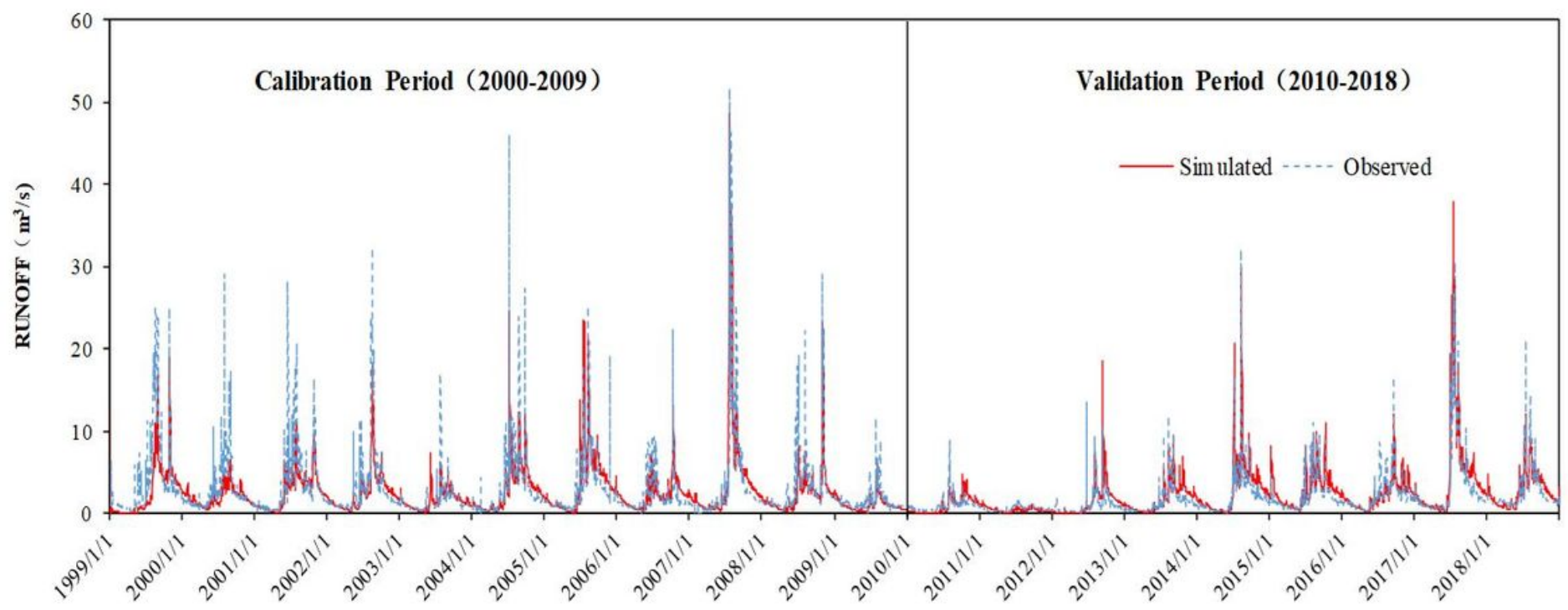

Figure 3

Model Fitness of Calibrated Hydrological Parameters for Sub-catchment 01. 

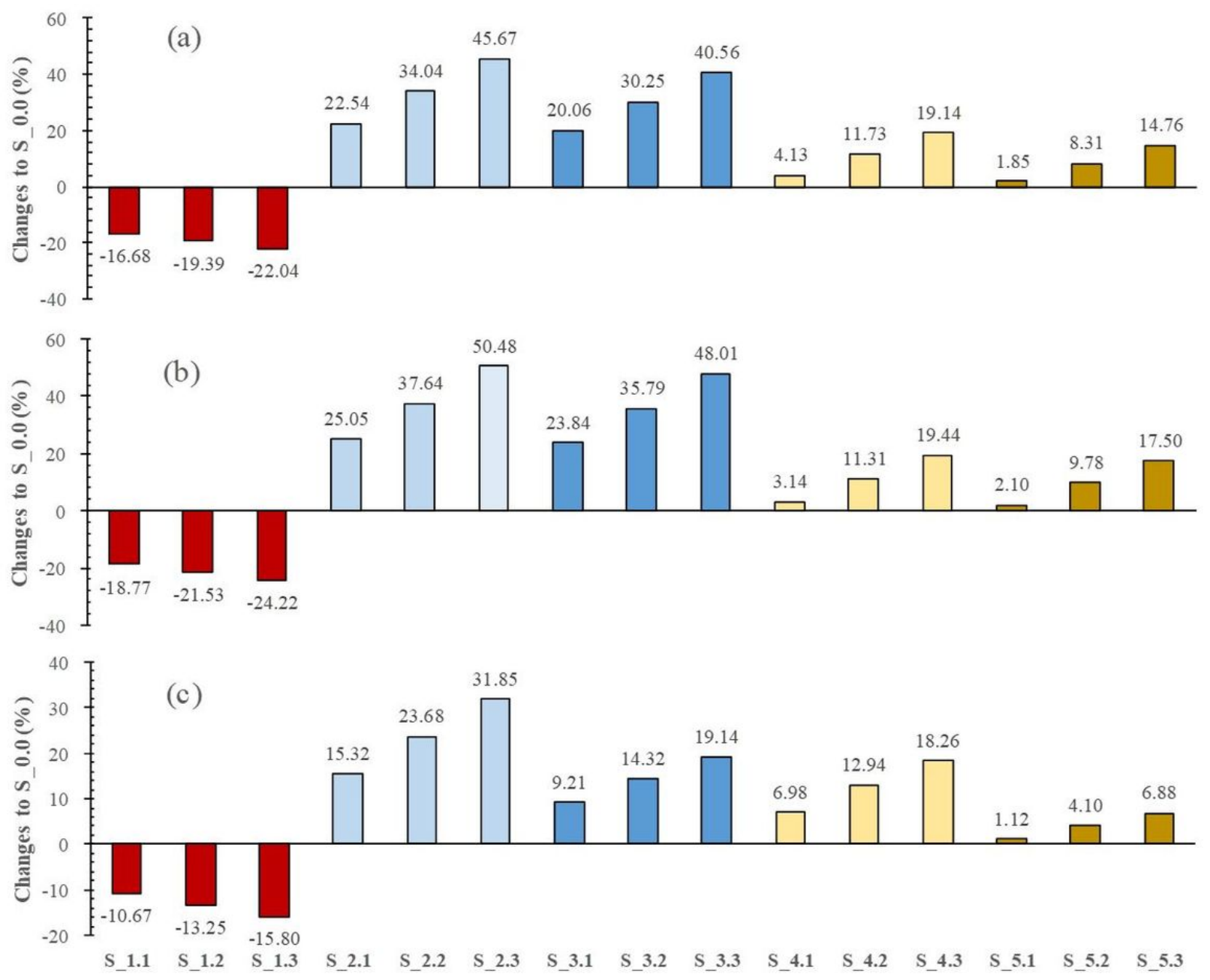

\section{Figure 4}

Runoff change under all fifteen climate change scenarios relative to the historical scenarios. (a), (b) and (c) are the changes of mean annual runoff (MAR), mean wet season runoff (MWR), and mean dry season runoff (MDR) respectively. 


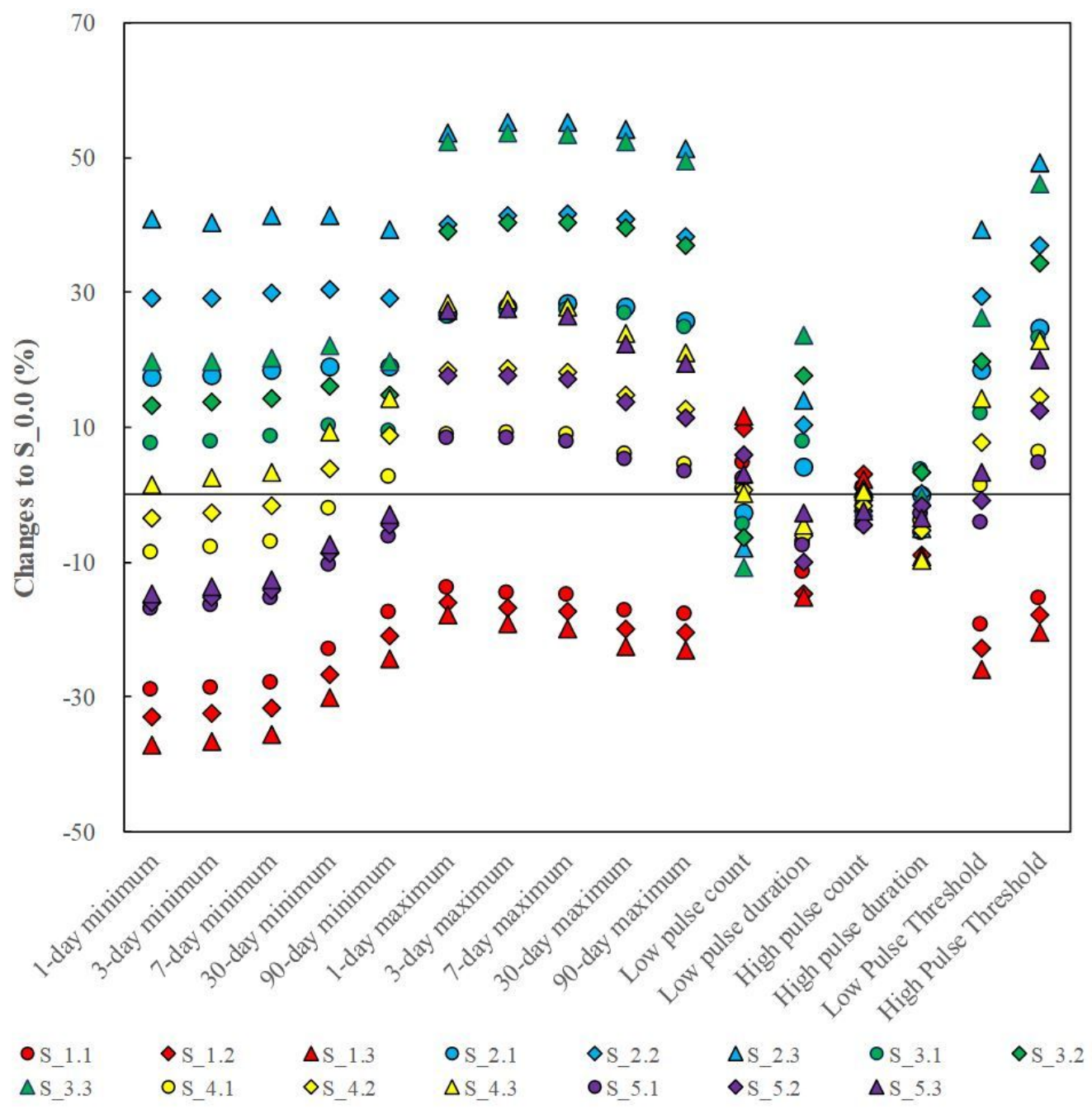

Figure 5

Changes of the 16 IHA indicators of the Lake Dianchi Basin under S_1.1-S_5.3 relative to S_0.0.

(a)
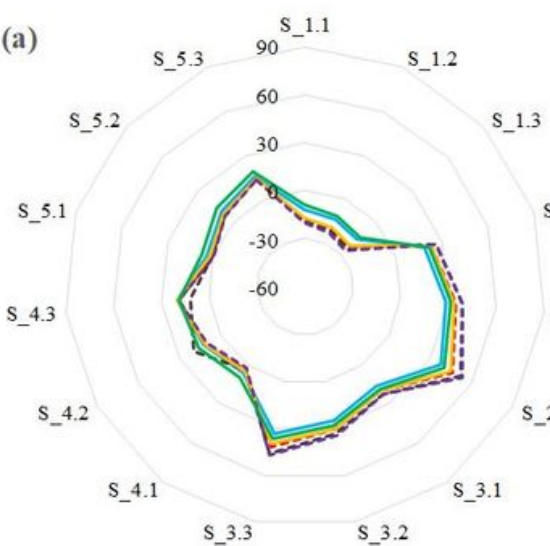

(b)

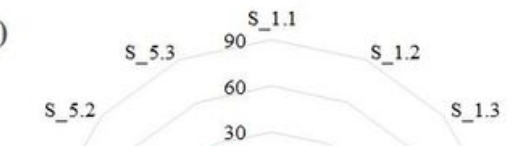

(c)

S_5.3 $90^{\text {S_1.1 }} \quad$ S_1.2
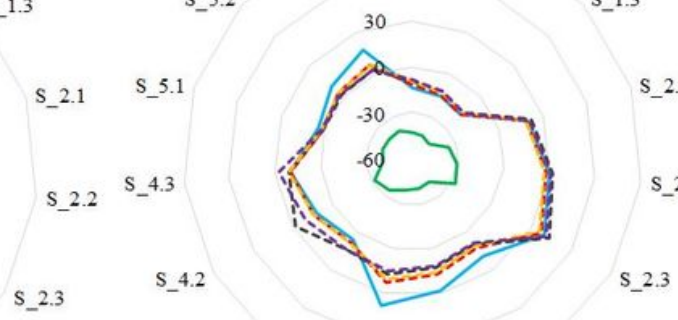

S_2.1

S_5.1

S_2.2 $\quad$ S 4.3

S 2.3

S_3.1

S_3.3 S_3.2

-----Sub_02

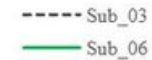

1.3

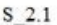

2.2

\section{Figure 6}

Changes (\%) of MAR (a), MDR (b), and MWR for all the six sub-catchments under S_1.1-S_5.3 relative to S_0.0. 
(a)

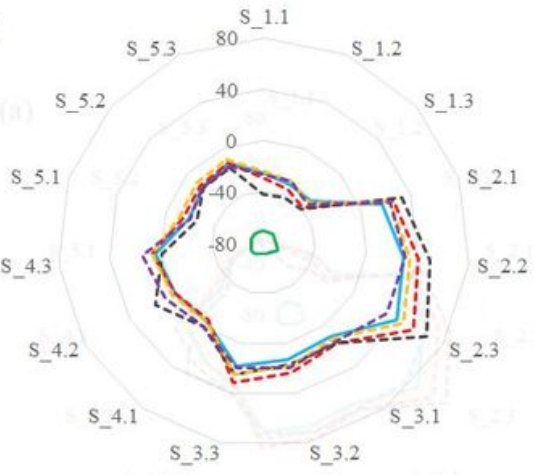

(d)

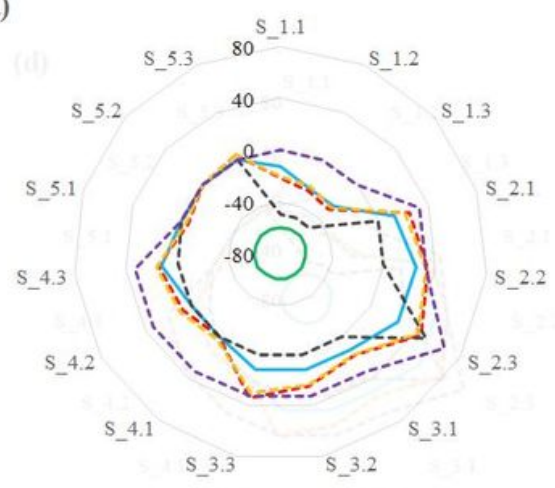

(b)

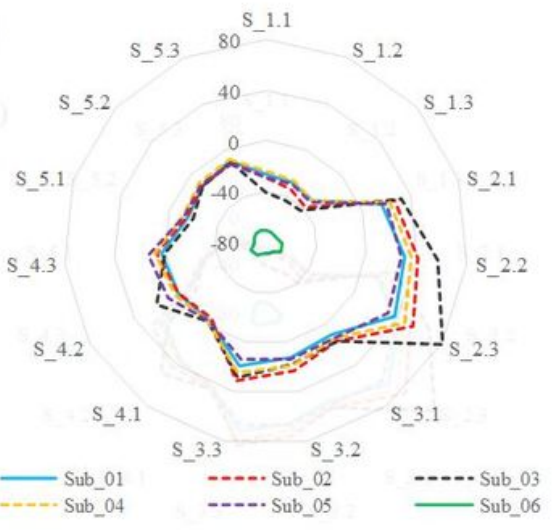

(e)

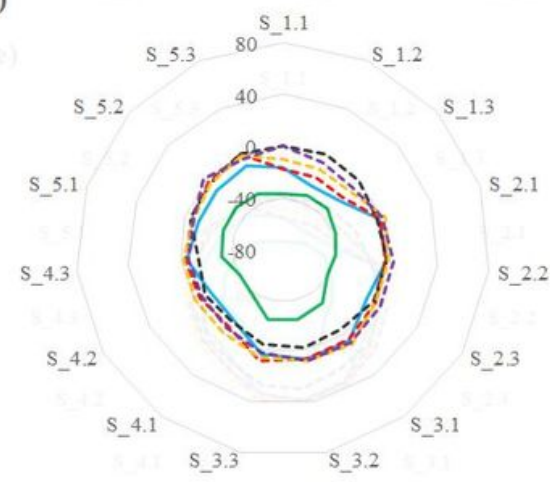

(c)

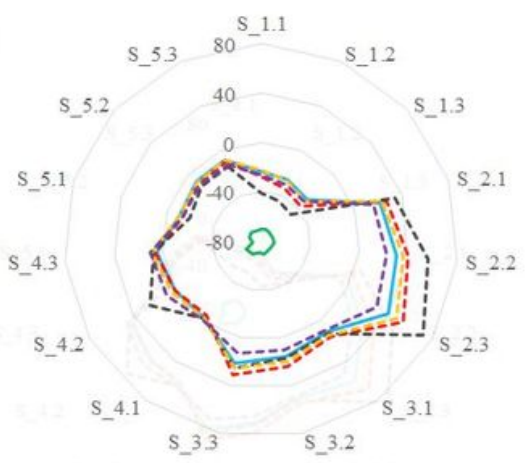

(f)

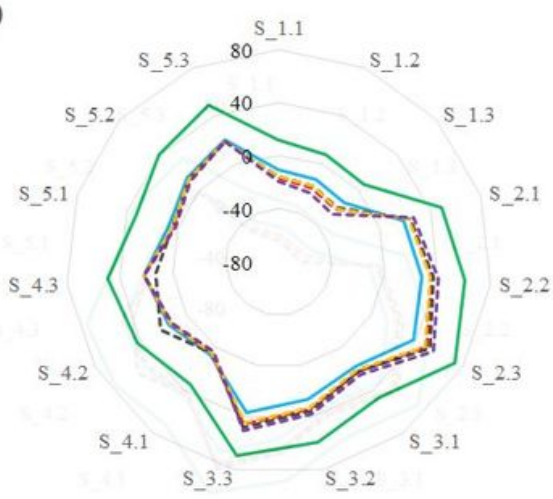

Figure 7

Changes (\%) of 1-day minimum runoff (a), 3-day minimum runoff (b) and 7-day minimum runoff (c), low pulse threshold (d), low pulse duration (e), and high pulse duration (f) for all six sub-catchments under S_1.1-S_5.3 relative to S_0.0. Only the indicators showed a high variation (|CV|>0.1) among Sub_01-Sub_05 are shown. Because the 1-day minimum and 3-day minimum have the same CV value, only the 1-day minimum is shown. 